\title{
MEASUREMENT OF ROTOR BLADE DEFORMATIONS OF WIND ENERGY CONVERTERS WITH LASER SCANNERS
}

\author{
M. Grosse-Schwiep, J. Piechel, T. Luhmann
}

\author{
Institute for Applied Photogrammetry and Geoinformatics, Jade University of Applied Sciences Oldenburg, \\ Ofener Strasse 16/19, 26121 Oldenburg, Germany - \\ (martina.grosse-schwiep, johannes.piechel, luhmann)@jade-hs.de
}

KEY WORDS: Laser scanning, photogrammetry, synchronicity, wind energy converter, rotor blade deformation

\begin{abstract}
:
Wind energy converters in operation are exposed to high stresses which result in large deformations of the rotor blades. In this paper, a method for determination of deformations of rotor blades is presented using multiple synchronous laser scanners and cameras. A special focus is brought into the twist of the blade and the according deflection. In a first step, multiple scanners in 1D mode are used which record cross sections at different positions along the rotor blades. By comparison with the CAD model, deformations can be derived. In order to ensure that the positions of the cross sections are defined in the coordinate system of the wind energy converter, the nacelle is pre-scanned and a transformation is performed using known coordinates from the manufacturer. To account for the relatively slow movement of the nacelle, it is observed by a photogrammetric camera. The results of the nacelle's motion are considered in the analysis of the 1D data. First test recordings were carried out with different measurement frequencies to enable comparisons of accuracy. Furthermore, the first results of the cross-sections are presented.
\end{abstract}

\section{INTRODUCTION}

The objective of the project WindScan, managed by the Jade University of Oldenburg, is the detection of deformations of a moving rotor blade in 1:1 scale with several synchronously operated laser scanners. A very large wind energy converter (WEC) is observed during operation whereby the rotor blades are of particular interest.

Within the research project, cooperations with the following companies / institutions are established:

- Zoller+Fröhlich $(\mathrm{Z}+\mathrm{F})$ - manufacturer of laser scanners

- REpower Systems SE - manufacturer of WEC

- HafenCity University Hamburg (HCU)

- Surveying office Dr. Hesse und Partner Ingenieure.

At least two scanners take cross sections in 1D mode which will be compared with a CAD model in order to derive dynamic deformations of the blades. For the transformation of the coordinate systems of the scanners into the system of the WEC, the nacelle has to be scanned in 3D-mode first. The movements of the tower and the nacelle are measured by photogrammetry.

\section{BASICS AND STATE OF THE ART}

\subsection{Laserscanning}

Most common applications of laser scanning are concerned with capturing of static objects. Different operating modes are possible, the principle is shown in Figure 1. The sequential acquisition of individual points results from the rotation of the laser around the horizontal and vertical axis (3D). Alternatively, typical mobile mapping systems use the rotation of only one axis (2D) while the movement of the mobile platform of the scanner provides the third dimension. For allocation/referencing other sensors such as GPS, INS or cameras are necessary (ElSheimy, 2005, Boeder, 2010).
On the other hand, a moving object can be observed from a fixed position and with a fixed orientation (1D). For the allocation of the measured points the orientation and position of each measurement has to be acquired with additional sensors. In Wujanz et al. (2013) an investigation is presented dealing with the recording of a moving ship. The movements were registered by three target-tracking total stations for the geometrically correct registration of the point cloud. The ship itself was assumed to be stable. The synchronization of the total station and the scanner was done by synchronized watches.

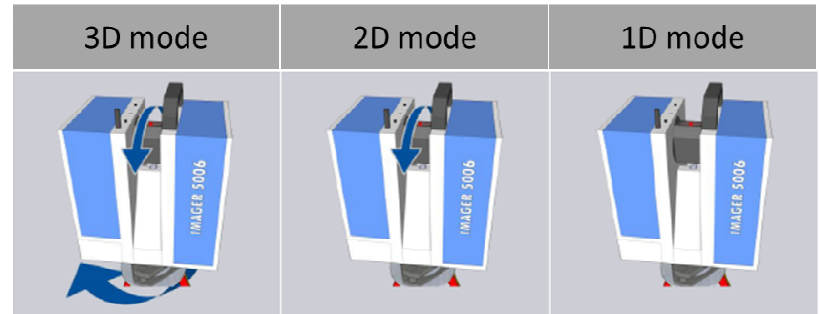

Figure 1. Operating modes of the laser scanner (Kutterer, 2009)

\subsection{Wind energy converter}

Within the research project WindScan, wind energy converters (WEC) are used as measuring objects. The rotor blades of the WEC are a key component for increasing their performance. Blades are constantly being optimized to save costs and improve efficiency (Zerbst 2010).

The measurement object is a six megawatt unit ("6M") of REpower System SE (REpower, 2013), designed for offshore use and installed on land in northern Germany. It has a hub height of $100 \mathrm{~m}$, a blade length of $61.5 \mathrm{~m}$, and the nacelle measures approximately $17 \mathrm{~m} \times 7 \mathrm{~m} \times 6 \mathrm{~m}$.

Changes of wind direction can be detected by sensors. When a certain value is exceeded, the nacelle is moved towards the direction of the wind. This may happen with irregular intervals and is highly depending on the current wind conditions. The 
data from other sensors such as alignment of nacelle and wind speed are of additional use for the laser scanning analysis. Also, the rotational speed and selected coordinates of significant points of the turbine are needed, as well as CAD models of the nacelle and of the rotor blades.

WEC are subject to particular stresses which can be critical due to their continuous change, especially caused by wind pressure, centrifugal forces and gravity. The top speed on the outer tip of the blade can reach up to $80 \mathrm{~m} / \mathrm{s}$ (revolution speed $7.7-12.1$ U/min (REpower, 2013)). These forces lead to bending of the blades of up to $10 \%$ of the blade length (Edzard, 2009). The rigidity of the blade decreases to the outer tip of rotor blades. Close to the hub a cross section amounts to several meters, which reduces to the tip. In addition to bending a torsion occurs (rotation within a blade) which is in turn dependent on the bending.

The tower curvature must not be neglected and varies over time. The effect can be sufficiently described as a shift of the nacelle in the horizontal plane.

More degrees of freedom are shown in Figure 2.

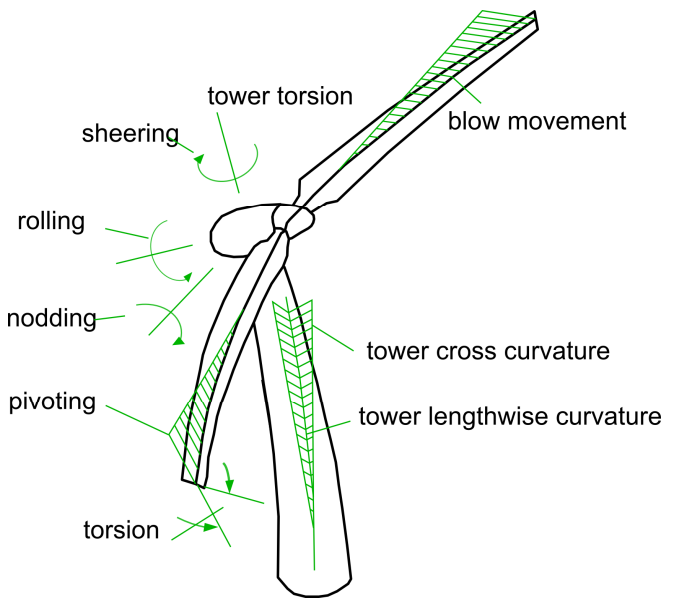

Figure 2. Degrees of freedom of the WEC (after Hau 2008)

\subsection{Previous survey of rotor blades}

Until now the blades are tested in large laboratories for certification by static or cyclic testing. In this case the blade is, for example, set in forced oscillation for a long time and observed by photogrammetric means (Hau 2008, IWES 2013, Aicon 2013). Bending tests also offer the possibility to measure the shapes of the blade and its changes.

For the ongoing operation only few research results are published. Schmidt Paulsen et al. (2009) attached reflective targets to rotor blades and tower, and observed them with two stereo systems. Another recent project concerning the capture of the aero-elastic deformation takes place at the Institute ForWind, a joint research center of the universities of Oldenburg, Hannover and Bremen (Winstroth \& Seume, 2012). Here, the blades are covered with a random pattern and observed with a stereo system. By matching procedures local deformations should be derived.

As a disadvantage of both projects the WEC has to be stopped for an extended period of time in order to glue the blades with a texture film and to remove them again later.

\section{THE WINDSCAN PROJECT}

The key objective of the WindScan project is the development of a method for measurement of bending and torsion of the blades without targeting of the system. The basic concept includes a combination of laser scanners and cameras which shall observe the WEC from the ground. The aim is to measure the blade in a horizontal position, whereby the position of the cross section related to the hub should be known better than $0.5 \mathrm{~m}$.

\subsection{Laser scanner}

For the determination of deformations, multiple $\mathrm{Z}+\mathrm{F}$ Imager 5010 are operated in 1D mode, i.e. vertical and horizontal angles are fixed. Since the beam is pointed to a fixed direction, this mode is classified as laser class $3 \mathrm{~B}$ and thereby dangerous (DIN 2008). For the duration of the measurement a special firmware is installed on the scanner. Moreover, during a measurement a $\mathrm{Z}+\mathrm{F}$ employee and a laser safety officer have to be present in order to avoid hazards.

For a measuring set a compromise between distance and angle of incidence has to be found. The shorter the distance, the more accurate the measurement and the smaller the spot size (about $30 \mathrm{~mm}$ at $100 \mathrm{~m}$ ). The incident angle is also dependent on the current position of the rotor blades. Depending on wind strength they can entirely rotate around then longitudinal axis ("pitch"). A clearance of $50 \mathrm{~m}$ and a hub height of $100 \mathrm{~m}$ results in a measuring distance of $110 \mathrm{~m}$ and an elevation angle of $63^{\circ}$ (Figure 3). Thus the unambiguity interval of the scanner of $187 \mathrm{~m}(\mathrm{Z}+\mathrm{F} 2013)$ is not exceeded even if the nacelle rotates.

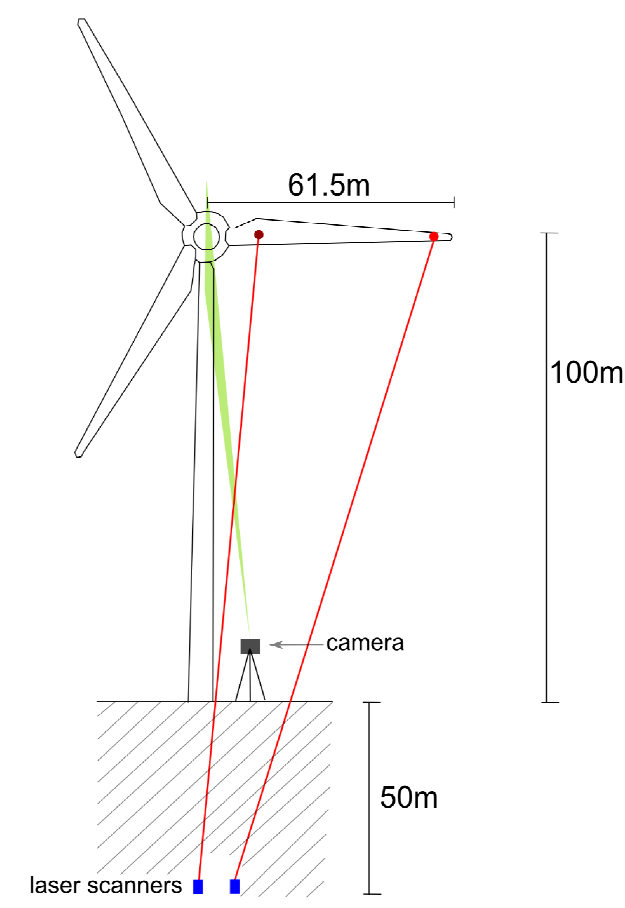

Figure 3. Measuring arrangements on WEC

With rotating blades and a fixed laser beam, the distances form a cross section of one side of the blade. Paffenholz et al. (2008) and Gikas \& Daskalakis (2009) have also recorded such cross sections with a laser scanner, which, however, were not further analyzed in their pilot projects. 
The deformations are derived from the cross sections taken at different positions on the blade (Figure 3). By fitting the cross sections into a CAD model of the blade, the deformations can be calculated.

Figure 4 shows the arrangements of the camera and laser scanners in front of the WEC during the measurement.

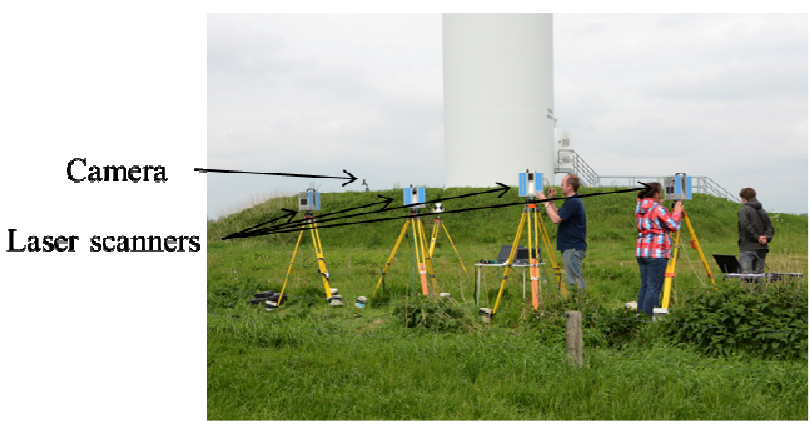

Figure 4. Measuring arrangement of the camera and laser scanners

In order to synchronize the scanners $\mu$-blox GPS modules are used. The start time (UTC) of the measurement is written into the header of the file and every second a marker is registered. Synchronization is only necessary for the allocation of the cross sections to the same blade at the same cycle. Therefore a high precision is not necessary. The calculation of the time stamp for each measurement point is done with the software development kit of the manufacturer. As a prerequisite for a correct referencing of the measured values to the coordinate system of the WEC, a standstill of the nacelle during the 3D scans is required. In contrast, during the measurement of the profile the movements are registered by photogrammetric means and taken into account by the following calculations.

\subsection{Camera}

In order to separate deflections of the rotor blade from rotations of the nacelle, which both affect the measured distance, the nacelle is observed continuously with a camera (Nikon D2X). A hub height of $100 \mathrm{~m}$ and a length of the nacelle of $17 \mathrm{~m}$ lead to a focal length of about $130 \mathrm{~mm}$ for the complete exploitation of the image format (a $200 \mathrm{~mm}$ zoom lens is used).

The camera mode "interval record" is used which records an image every second, limited to 999 images. This represents a recording time of about 15 minutes.

In order to synchronize the camera with the scanned data also a GPS module is used. This module writes the UTC time into the header of each image.

The images are analyzed with the institute's program PISA (Photogrammetric Image Sequence Analysis (Bethmann et al. 2011)). In this step a point tracking of prominent points is done by least-squares matching, thus the displacement and rotation of the nacelle can be calculated. The scale of the image is derived from known dimensions of the nacelle, supplied by the manufacturer of the WEC.

\subsection{Process of measurements}

The cross-sections of the WEC should be taken in horizontal blade position. However, each rotation of the nacelle changes position and height of the impact point on the rotor blade.
In advance, 3D scans are performed with all scanners in order to determine their orientation. In Figure 5 the point cloud of a 3D scan of the nacelle is shown. The stripes are hits on the rotor blades, resulting both from the movement of the blades and the scanner. Each stripe consists of several profiles taken at different positions. In Figure 6 the data is combined with the CAD model using the software Geomagic Qualify 2012. In these scans, the angles for the following 1D mode are picked. Then the nacelle is scanned again just to reduce the recording time, because no movement of the nacelle should occur during these reference scans. This can be checked with the recorded camera images.

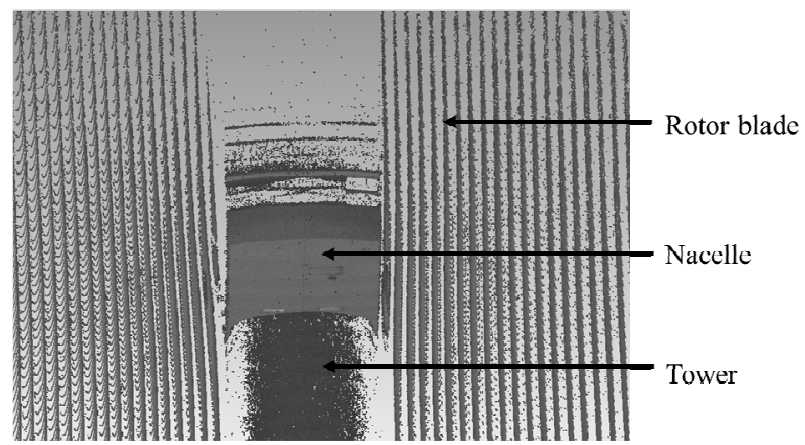

Figure 5. Point cloud of 3D scans of the nacelle. Stripes are hits on the rotating blades.

For the following calculation two points of the nacelle with known coordinates are required, as well as the measured vertical and horizontal angles and distances. Thus, the position and orientation of the scanner relative to the coordinate system of the hub are determined.

Afterwards the bearing of the 1D measuring beams will be fixed. The measurement time is approximately three minutes. Here, a cross section of the rotor blade is recorded, which is slightly inclined depending on the orientation. At the same time, the camera observes the nacelle and the operational data of the turbine is recorded.

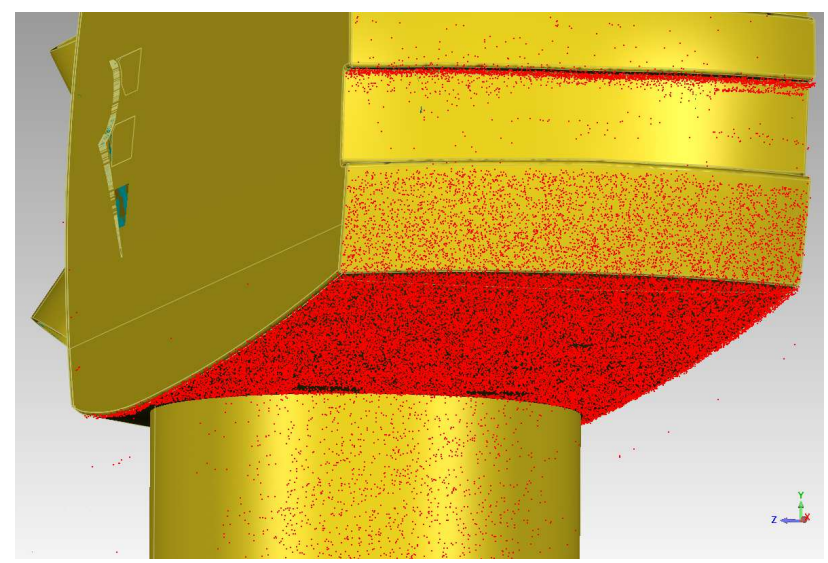

Figure 6. Point cloud of 3D scans combined with a CAD model

\subsection{Calculation procedure}

The scan data are initially given in the coordinate system of the instrument. It is common practice to transform the data into a local stationary system (Niemeier \& Wild, 1995), equally for all scanner positions. In the current work, the motion of the object is a critical issue. 
To make the results useful e.g. for the manufacturer, a transformation into the coordinate system of the object is essential; here the coordinate system of the hub (GL 2012) is used.

The analysis is done separately for position and height. In order to obtain the results relating to the target coordinate system (the hub / the blade), the axes of rotation and some distinct points are necessary.

\subsubsection{Calculation of position}

In the first step, the position of each scanner is calculated in the hub coordinate system. The known coordinates of the nacelle and the 3D scans of the nacelle are utilized. With the measured values of at least two points simple triangle calculations can be carried out. Redundant measurements are used for control and later for increasing the accuracy by adjustment. Comparisons using the 3D scan data lead to discrepancies in the scanner positions of a few centimetres which meets our expectations.

As results, the positions of the scanner with respect to the hub at the time of the 3D reference measurement are given. Subsequently they will be related to the time stamps of the profile measurement using the results of the photogrammetric analysis of the PISA program.

The current positions of the survey stations, the horizontal angles, and the measured distances lead to coordinates of all profile points in the coordinate system of the hub.

\subsubsection{Calculation of height}

The heights of the instruments during the 1D measurement and the heights of the profile points in relation to the rotational center of the hub result from the distances and the vertical angles. For this at least one of the points on the nacelle must be known.

Subsequently, the rotation of the blade is considered. As starting point we use the first measured point on each rotor blade on each cycle leading to the current angular position of the blade and the radial distance from the axis. The coordinates of the sequence of all following points are derived by means of the time intervals in order to convert the function of time into a function of position. The length of the arc and corresponding coordinate changes (vertically, to a minor extent also horizontally) are calculated with the known measurement rate of the scanner and the rotational speed of the blade. The rotational speed can be derived from the registered operational data, or from the data taken in 1D mode, in which the revs of the rotor blades are counted.

\subsubsection{Accuracy and error propagation}

In order to estimate the achievable accuracy and to identify the critical parameters, the following cases are distinguished:

- A change in the nominal coordinates of the given points in the order of $2 \mathrm{~cm}$ causes offsets of up to $8 \mathrm{~cm}$ in the direction of the axis of rotation. In the radial direction, maximum change is about 2 to $3 \mathrm{~cm}$.

- Uncertainties of $0.02^{\circ}$ in the horizontal directions lead to maximum displacements of $2 \mathrm{~cm}$ (radial) or $0.1 \mathrm{~cm}$ (axial direction).

- Deviations of the distances of $1 \mathrm{~cm}$ add up to deviations of more than $1 \mathrm{~cm}$ radially and up to $5 \mathrm{~cm}$ in the axial direction.
- If the rotation rate (in seconds / revolution) is calculated incorrectly by $0.1 \mathrm{~s}$, one can expect a radial error of $0.3 \mathrm{~cm}$ and $2.5 \mathrm{~cm}$ in the vertical direction.

Thus the critical parameters are the target coordinates supplied by the manufacturer. The interpretability of the point clouds, in which the striking points are selected (e.g. the lower corners of the nacelle, see Figure 6), acts also as an error in the coordinates. The total error of all components does not exceed $20 \mathrm{~cm}$. Thus, the specified absolute position accuracy of the cross section related to the hub of $50 \mathrm{~cm}$ can be obtained. It is important to note that the relative accuracy within one profile is much higher.

\section{RESULTS}

In the following first results are presented dealing with tests of acquisition rates and with first analysis of profiles, which already show the bending of the rotor blades. Also first photogrammetric results are briefly described.
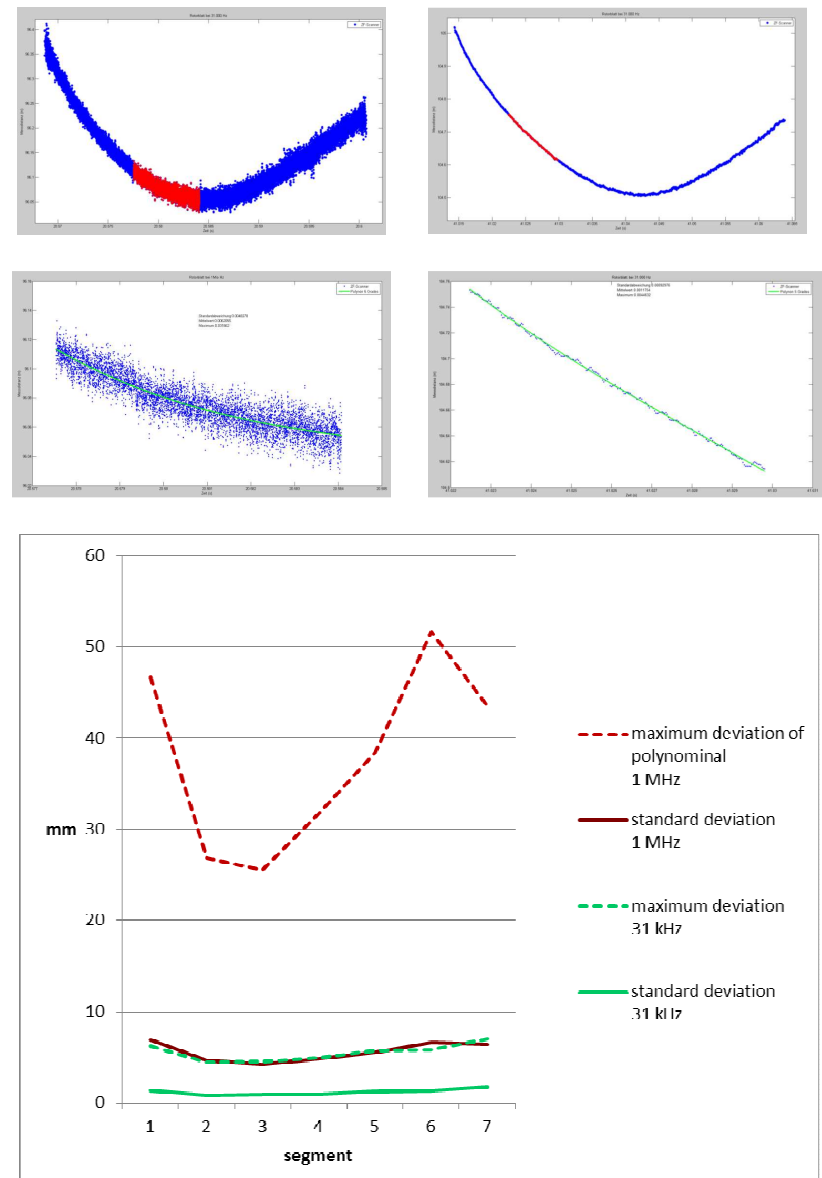

Figure 7: Top: recorded profile, left: $1 \mathrm{MHz}$, right: $31 \mathrm{kHz}$; middle: partial sections of the profile, left: $1 \mathrm{MHz}$, right: $31 \mathrm{kHz}$; bottom: maximum deviations from the polynomial and standard deviations

\subsection{Investigation of the measurement frequency}

The scanner is able to record data at a sampling frequency of up to $1 \mathrm{MHz}$. However, with a lower sampling rate, the distances can be detected more accurately, since the device has a longer integration time for disposal of a single measurement (Vennegeerts \& Kutterer, 2007). In this specific application, 
such a high number of points is not necessary to describe the shape of the rotor blade.

In order to test this in practice, cross-sections were recorded at different frequencies $(1 \mathrm{MHz}, 500 \mathrm{kHz}, 250 \mathrm{kHz}, 125 \mathrm{kHz}, 62$ $\mathrm{kHz}$ und $31 \mathrm{kHz}$ ).

In Figure 7 a cross section of a rotor blade is shown, recorded by $1 \mathrm{MHz}$ (top left). Immediately apparent is the high number of points and the higher noise compared to $31 \mathrm{kHz}$ measurements (top right).

In order to quantify the noise, the point cloud is approximated by a polynomial. Since polynomials of higher degree yielded no satisfactory adapting, the profile was divided into seven sections, each requiring its own polynomial. These polynomials, standard deviations, and maxima were calculated. At $31 \mathrm{kHz}$ the standard deviation is less than $2 \mathrm{~mm}$ and the maximum error is equal to $7 \mathrm{~mm}$. By comparison, at $1 \mathrm{MHz}$ standard deviations increase to $9 \mathrm{~mm}$ and the maximum error to $50 \mathrm{~mm}$.

For this reason, all the following measurements were carried out with a frequency of $31 \mathrm{kHz}$.

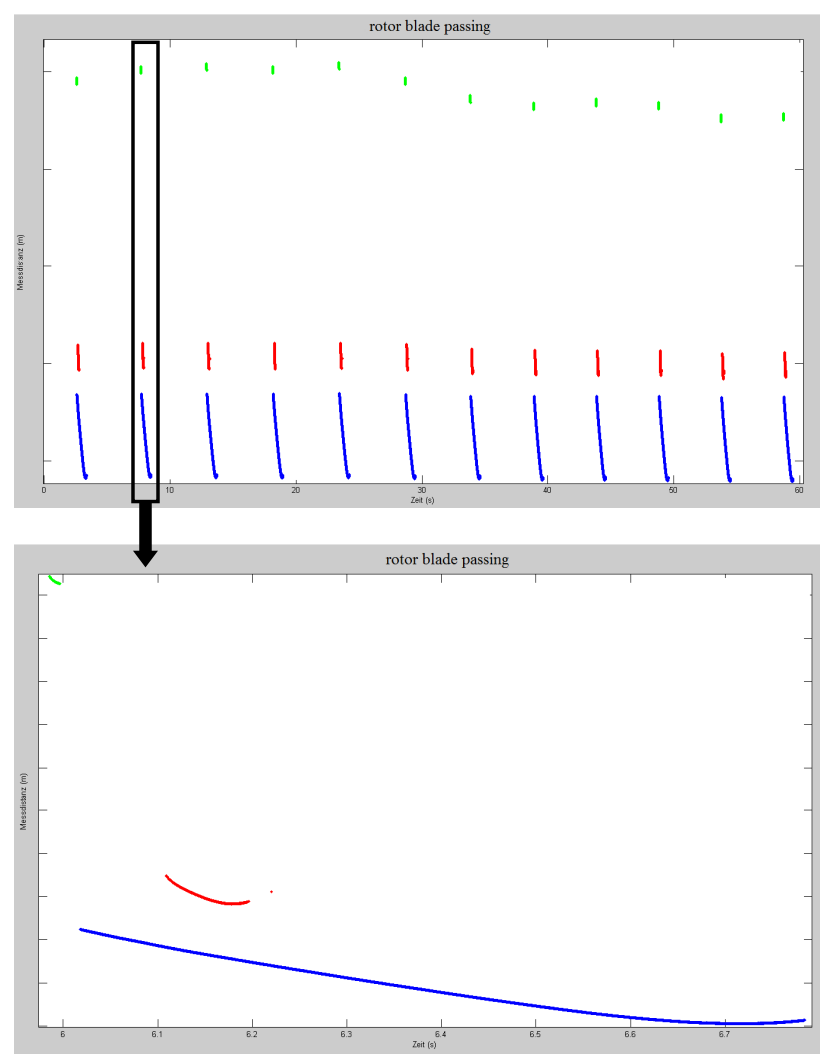

Figure 8: top: recorded profiles of one blade by three scanners for 60 seconds, bottom: recorded profiles of one blade in one cycle; blue: close to the hub, red: center; green: outer tip

\subsection{Results of multiple profiles}

For the determination of the bending and torsion at least two scanners are required. In our last measurement three scanners were operated simultaneously. In Figure 8 (top), the recorded data of three scans of one rotor blade in 60 seconds in 1D mode are shown. Data of the scanner, measuring a few meters away from the hub, are displayed in blue. In red the scanner is pointing to the middle and in green close to the outer tip of the rotor blade.

Since the difference of distance measurements does not exceed a certain limit, it can be concluded that at this time no nacelle rotation has occured. However, changes of distances in the green profiles are visible, indicating a variation of bending of the rotor blade.

Figure 8 (bottom) shows in detail only one rotor blade passing, measured by three scanners. At the outer tip of the blade (green) more than 300 points were recorded.

For the determination of the individual torsion, profiles are matched to a CAD model.

\subsection{Results of the photogrammetric evaluation}

By evaluating the photogrammetric data, significant shifts and rotations of the nacelle can be identified and determined. Figure 9 (top) shows the first and the last image of a sequence where the rotation is clearly visible. In green the measured points are marked. The rotation is illustrated in Figure 9 (bottom).
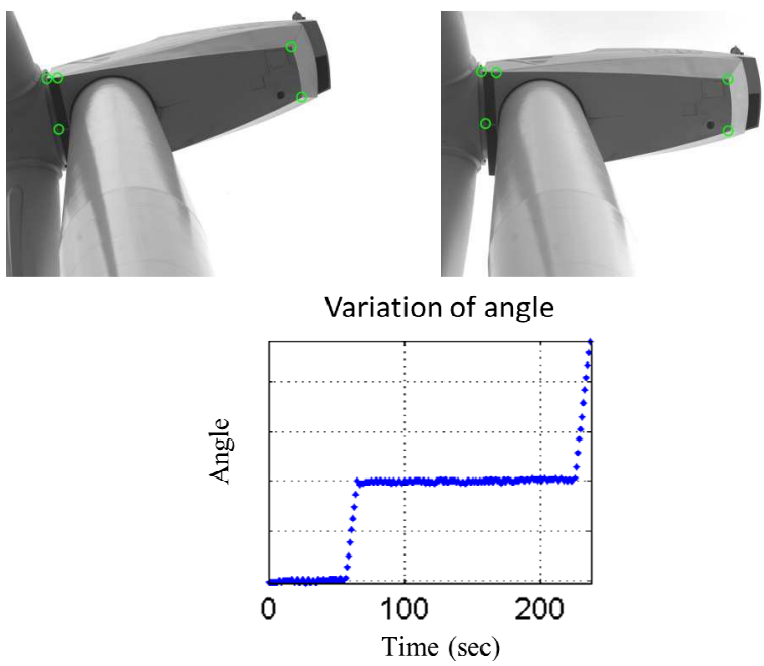

Figure 9. Rotation of the nacelle

\section{CONCLUSIONS AND OUTLOOK}

In the present work, a wind energy converter is analyzed during operation with multiple synchronous laser scanners. In order to quantify the deformations of the blades, cross sections are taken in 1D mode of the scanners. For orientation of the scanners into the hub coordinate system, 3D scans of the nacelle are carried out. The movement of the nacelle it is observed by photogrammetric means.

First major measurements have been completed recently. Detailed analyzes are still under progress. However, the data look very promising. In addition the calculation process will be further automated.

Next measurements are already planned and will be carried out simultaneously with the photogrammetric measurement of the ForWind institute. As a result, comparative data are expected that will be helpful in evaluating the results. 


\section{REFERENCES}

References from Journals:

Bethmann, F., Luhmann, T. (2011). Least-squares Matching with Advanced Geometric Transformation Models, International Archives of Photogrammetry, Remote Sensing and Spatial Information Sciences, Vol. XXXVIII, Part 5 Commission V Symposium, Newcastle upon Tyne, UK. 2010.

Kutterer, H., Paffenholz, J.-A., Vennegeerts, H. (2009). Kinematisches terrestrisches Laserscanning. Zeitschrift für Geodäsie, Geoinformation und Landmanagement (zfv), 2/2009, 134. Jahrgang, Wißner-Verlag, Augsburg.

Zerbst St., Knops M., Haase K., Rolfes R., 2010. Schadensfrüherkennung an Rotorblättern von Windenergieanlagen. Lightweight Design 3(4), pp. 16-24, Vieweg+Teubner Verlag.

\section{References from Books:}

Hau, E. 2008. Windkraftanlagen - Grundlagen, Technik, Einsatz, Wirtschaftlichkeit, Springer, Berlin, pp. 233 \& 437, ISBN: 978-3-540-72150-5.

\section{References from Other Literature:}

Böder, V. (2010). HCU-HMSS: A Multi Sensor System in Hydrographic Applications. In: Schulze-Lammers, Kuhlmann (Eds.), $2^{\text {nd }}$ International Conference on Machine Control\&Guidance. Bonn. March 9-11, 2010: pp. 65-74.

DIN, 2008. Sicherheit von Lasereinrichtungen - Teil 1: Klassifizierung von Anlagen und Anforderungen (IEC 608251:2007);

Safety of laser products - Part 1: Equipment classification and requirements (IEC 60825-1:2007); German version EN 60825$1: 2007$.

El-Sheimy, N., 2005. An Overview of Mobile Mapping Systems. FIG Working Week 2005 and GSDI-8, Cairo, Egypt April 16-21, online publication, $24 \mathrm{p}$.

Gikas V., Daskalakis S. 2009. "Contribution of Combined RTS and TLS to Dynamic Monitoring of Wind Energy Turbines", $9^{\text {th }}$ Int. Conference on Optical 3-D Measurement Techniques, Vienna, Austria, July 1-3.

GL 2012. Rules for Classification and Construction - Industrial Services "Guideline for the Certification of Offshore Wind Turbines", Germanischer Lloyd WindEnergie GmbH, Edition 2012, Hamburg, Germany.

Muammer Ozbek, Daniel J. Rixen, Theo W. Verbruggen 2009. Remote monitoring of wind turbine dynamics by laser interferometry: Phase1, Orlando, Florida USA, Society for Experimental Mechanics Inc.

Paffenholz, J., A., Vennegeerts, H., Kutterer, H., 2008. High frequency terrestrial laser scans for monitoring kinematic processes, Proceedings of the INGEO 2008, Bratislava, Slovakia.

Niemeier W., P. Wild (1995). Use of Laserscanners for the Determination of Building Geometries. Gruen/Kahmen (Eds.): 3D Optical Measuring.
Schmidt Paulsen, U., Erne O., Schmidt, T., 2009. Wind Turbine Operational and Emergency Stop Measurements Using Point Tracking Videogrammetry, Proceedings of the SEM Annual Conference, Albuquerque, New Mexico, USA.

Vennegeerts, H.; Kutterer, H., 2007. Analyse der Bewegung von Windenergieanlagen aus dem Vergleich zweier Aufnahmeverfahren terrestrischer Laserscanner. Brunner, F.K. (Hrsg.): Ingenieurvermessung 07 - Beiträge zum 15. Internationalen Ingenieurvermessungskurs, Graz, Wichmann, Heidelberg, 335 - 340.

Winstroth, J. and Seume, J. R., 2012. New Test Bench for Optical Measurments of Rotor Blade Deformations on Wind Turbines, Proceedings of 8th PhD Seminar on Wind Energy in Europe, ETH Zurich, September 2012, unpublished.

\section{References from websites:}

Aicon, 2013. Rotor blade testing at the IWES, Braunschweig, Germany, http://www.aicon3d.com/applikationen/portablekoordinaten-messtechnik/dynamisches-messen/iwes.html $\quad$ (05 Jun. 2013)

IWES, 2013. Test Centers, Rotor Blade Testing, Bremerhaven, Germany http://www.iwes.fraunhofer.de/en/labore/Rotorblatt.html Jun. 2013)

Edzard, H., 2009. Rotorblatt für Windkraftanlagen, insbesondere für schwimmende Windkraftanlagen, sowie Windkraftanlage mit einem Rotorblatt, Germany http://www.patent-de.com/20090212/DE102007036917A1.html (10 Jun. 2013)

REpower, 2013. 6M, "Technical Data”, Hamburg, Germany http://www.repower.de/fileadmin/produkte/6m/RE_6M.pdf (05 Jun. 2013)

Z+F, 2013. Z+F IMAGER 5010, 3D Laser scanner, Technical Data, Wangen, Germany http://www.zf-laser.com/fileadmin/editor/Datenblaetter/Data sheet_Z_F_IMAGER_5010_E_kompr_01.pdf (05 Jun. 2013)

\section{ACKNOWLEDGEMENTS}

The authors gratefully acknowledge the financial support by the German Federal Ministry of Education and Research (BMBF), project funding reference number 17017X11. 